\title{
The Impact Of Cultural Differences On The Effectiveness Of Advertisements On The Internet: A Comparison Among The United States, China, And Germany
}

Edward C. Miller, Nova Southeastern University, USA

Thomas Griffin, Nova Southeastern University, USA

Peter Di Paolo, Nova Southeastern University, USA

Ed Sherbert, Nova Southeastern University, USA

\begin{abstract}
Hall and Hall (1990) classify German culture as a low-context culture, American culture as a medium/low-context culture, and Chinese culture as a high-context culture. A low-context culture is one where the words contain most of the information needed and there is little need to rely on the context of the events/message to help interpreting the meaning of the message/events. In contrast, a high-context culture is one where the context of the message is as important as or even more important than the words. This paper focuses on selected cultural differences among Germany, United States, and China, and the impact of these differences on the various aspects of consumer behavior. Specifically, it is focusing on the impact of cultural context on the effectiveness of the different styles of advertising.
\end{abstract}

Keywords: context culture, advertising

\section{INTRODUCTION}

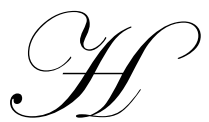

all and Hall (1990) classify German culture as a low-context culture, American culture as a medium/low-context culture, and Chinese culture as a high-context culture. Different culture will affect customers' perceptions on the advertisements (Ad). This paper intends to find out the impact of culture context on effectiveness of different styles of advertising. The research questions are: (1) Do low-context and high-context cultures differ in the amount of verbal information they need? (2) If an Internet advertisement contains only pictures, will the amount of information extracted from the Ad very greatly, depending on the context of the culture? This research aims to help managers to use Ad to convey the information more appropriately and effectively.

\section{LITERATURE REVIEW}

There are several definitions of culture with a society. Ball and McCulloch (1985) believe that most professionals view culture as the sum of beliefs, rules, techniques, institutions, and artifacts that characterize human populations.

Engel, Blackwell, and Miniard (1986) define culture as complex values, ideas, attributes, and other meaningful symbols that serve humans to communicate, interpret, and evaluate as members of society. Furthermore, the authors believe that humans develop their values by socialization and acculturation. Socialization is the process of absorbing ones culture. Acculturation is the process of learning a new culture. This occurs when a consumer moves to a new country or changes group identity. 
Similarly, Stanton, Etzel, and Walker (1994) define culture as symbols and artifacts created by society and handed down from generation to generation as determinants and regulators of human behavior. The symbols/artifacts may be intangible (attitudes, beliefs, values, and language) or tangible (tools, housing, and products).

In addition to cultural studies there are cross-cultural studies. Cross-culture analysis is the systematic comparison of similarities and differences in the material and behavioral aspects of different cultures (Engel, Blackwell, and Miniard, 1986).

There are many cultural differences among Germany, United States, and China. One significant difference among the Germans, Americans, and Chinese is the degree of context their culture depends. Hall and Hall (1990) classify German Culture as a low-context culture, American culture as a medium/low-context, and Chinese culture as a high-context culture. People in low-context cultures need detailed background information each time they interact.

In a high-context culture the context of the message is as important or more important than the words. This implies that not only the content of the message is interpreted, but also the context or situation in which the message occurs. The context of a verbal exchange includes the social setting, the use of phrasing, gestures, tone of voice, the person's history, status, and posture (Kennedy and Everest, 1991). Consequently, the need for detailed verbal communication is greatly reduced. High-context people tend to leave some things to imagination rather than explaining in detail and prefer subtlety and tact to frankness and fact. Examples of high-context cultures include Japanese, Koreans, Chinese, French, Arabs, and Mediterranean people (Hall and Hall, 1990).

Business practices may be impacted by the differences between high- and low-context cultures. Highcontext cultures tend to let information flow more freely whereas low-context cultures tend to control the information. For example, in low-context cultures, top executives control the content and flow of organizational information and the information tends to originate from a few people and sources. Where as in a high-context culture the entire organization is based on gathering, processing, and disseminating information. People are constantly gathering and giving information to stay informed about every aspect of the business. In addition, everyone knows who is best informed and on what subjects (Hall and Hall, 1990). Therefore, high- and low-context cultures tend to have difficulties communicating to each other.

Figure 1: Low to High Cultural Continuum

\begin{tabular}{cccc}
\hline & & & \\
Low-----------Medium/Low---------Medium/High----------High \\
Germans & Americans & French & Chinese \\
\hline
\end{tabular}

Kennedy and Everest (1991) published a study on the influence of high- and low-context cultures on communication in the workplace. Several observations were presented where managers have different expectations from the employees on how a job should get accomplished. They concluded that if managers, usually from low- to medium-context cultures, understand how culture influences the behavior of people that work for them (mostly from high-context cultures), they will be able to respond to them more effectively.

In 1991, Dulek, Fielden, and Hill emphasized the importance of cultural context in effective international communication. They explained that in low-context cultures what counts most are what has been written and not the social situation under which the message takes place. In high-context cultures the opposite is true. In high-context cultures the social context in which an agreement is made counts as much as the written document. The authors believe that knowledge of where a country is on the continuum of low-versus high-context gives managers valuable information on how to communicate with people from other cultures. They provide three sets of guidelines for managers in international settings: conversational, presentation, and written. 
1. Conversational: A manager should be aware that high-context cultures want to know as much as possible about you and your company. People in high-context cultures prefer to learn about you before they meet you which can be accomplished by resumes, brochures, and annual reports.

2. Presentation: The majority of both high- and low-context cultures expect formality. Audiences in highcontext cultures expect presentations to be short, separate segments that allow time for questions and discussions. In addition, age is a determining factor. Therefore, when presenting or negotiating contracts with people in high-context cultures, an older more experienced executive might be more successful.

3. Written: Only in low-context cultures where communication efficiency is highly important should you organize your communications so that its main point is directly and immediately stated. People from highcontext cultures a brief, written statement is all that is required. In addition, in high-context cultures, there is an emphasis on politeness and respect and the written statements should reflect this.

In summary, cultural context is very important when communicating with different cultures, regardless of the mode of communication, conversational, presentations, or written.

In addition to research on the impact of cultural context on management practices and communication in international business, there are studies examining the impact of cultural context on marketing effectiveness. Cutler, Javalgi, and Erramilli (1992) examined the belief that national cultural differences influence advertising practices, and the fact that these influences should be observable at the component level of the different ads. They conducted a five-country content analysis on visual components of print advertising. The countries include two low-context cultures, the United States and the UK, and three high-context cultures, France, Korea, and India. The research contrasts the visual components of the print advertising in these five counties.

The study showed that French ads are the largest in absolute size and percentage of the page for both durable and non-durable goods while the United States ranked intermediate. Furthermore, the French showed the product 49 percent of the time compared to Korea that showed the product in 72.5 percent of the advertisements. The United States was in an intermediate position with 57.3 percent. Therefore, global standardized advertising will not be effective as individual advertising.

Miracle, Chang, and Taylor (1992) published a study focusing on the difference between United States and Korean television advertising practices. They argued that high-context cultures, such as the Korean culture, tend to use indirect and ambiguous messages whereas low-context cultures, such as American culture, tend to use clearly articulated and spoken messages. They found that almost every Korean commercial identified the company in the advertisement, compared to the United States where only 56 percent of the advertisements show the company name.

In addition, the number of times the company name is mentioned in 15 -second commercials is significantly less in the United States than in Korea and significantly more in the United States than in Korea in 30-second commercials. Since people from high-context cultures tend to emphasize the whole picture, it is not surprising to see that Korean commercials identify company name and product specific information more often. The length of time the product/package, company, or brand name was on the screen was significantly longer for the United States commercials than for Korean commercials. This is consistent with the cultural-context, since Americans use direct messages to communicate in contrast to the Koreans who also use the background information to evaluate the product.

In conclusion, for advertising in a low-context culture to be effective, messages have to be direct and give a clear product description. In contrast, high-context ads should not only focus on the message, but also on the situation/context in which the message is given.

Many Americans perceive ads in the United States as having little informational value. Furthermore, Japanese advertisements are often perceived as being even less informative than American advertisements. In contrast, advertising in China and South Korea is highly regulated and therefore an assumption is made that it is straightforward and contains more information cues. 
Keown, Jacobs, Schmidt, and Ghymn (1992) examine the differences in advertising practice using a four country and four media analysis and incorporating Resnik and Stern's (1977) information classification system. This system classifies the information cues as follows: price or value, performance, availability, taste, guarantees or warranties, nutrition, company sponsored research, quality, components or contents, special offers, packaging or shape, safety, independent research and new ideas. Furthermore, they researched the information content of television commercials, radio, magazine, and newspaper advertising in the United States, Japan, South Korea, and China. The study found that different cultures have varying degrees of information cues in their advertisements and that the number and type of cues vary by media within each country.

Consistent with cultural-context expectations, American television commercials and radio advertising were found to have the highest average number of information cues per commercial, followed by the Japanese, the Chinese, and South Korean. However, contrary to the context-culture expectation, for magazine ads the Chinese ads came out on top, followed by the South Korean, Japanese, and American advertisements. The authors suggest the high number of information cues in magazine ads in China and South Korea was a result on the strict regulations in these countries.

Not only the number of cues per advertisement differs from country to country; the type of cues also differs from country to country. In the American media, product performance was the most emphasized information cue, followed by components and contents, and then availability of the product. In the Chinese media, quality was the most emphasized cue followed by availability, and performance. The authors concluded that there is a difference both in the types of and the number of information cues not only for the four countries, but also for each media within a country.

Zandpour, Chang, and Catalano (1992) examine the differences and similarities that might exist among American, French, and Chinese television advertising in terms of strategy, content, and execution form. Again, the Resnik and Stern's classification was used to evaluate the information content of the advertisements. The results show that French commercials are more likely to be dramatic with minimal copy, unlike the United States commercials, seldom directly address the audience with a lecture.

A high-context culture has less need for direct, verbal information. In addition, French and Chinese commercials are more likely to make explicit, unrealistic promises about the product. Unlike the United States, the French and Chinese tend to use symbolism with minimal copy and little brand visibility. Thus, copy is limited and more background information is provided in this culture type.

In addition, the Chinese commercials also generally link the product to the traditional Chinese values, a sign of a high-context culture. In contrast, United States commercials, originating from a low-context culture, are more likely to use celebrity reasoning in support of the product. These results confirm that different communication patterns exist in different counties and that the United States ads rely more on direct message.

Smith (1991) studied the effects of visual (high-context) and verbal (low-context) advertising content on consumer's inferences about missing product attributes. Smith's study showed that consumers construct similar inferences about unknown product attributes, regardless of the way they are communicated.

Research has shown that when both pictures and words are presented in an ad, the more vivid information will dominate attention and judgement. Smith (1991) confirmed that when an advertisement contains both explicit visual and explicit verbal claims about different product attributes, consumers' inferences about missing attributes would be dominated by the visual claim.

An important difference between the Chinese and Americans is their view on personal relationships. In China (high-context), business is based on the quality of personal relationships that exist between the buyer and the seller. The Chinese prefer to conduct business with people they know. Therefore, the Chinese want to first know you on a personal basis before actually doing business and are committed to people and relationships. They also have a strong tendency to build lifetime relationships (Hall, 1990). Therefore, when conducting business in a high- 
context culture it is important to establish personal relationships and convey as much about the organization you represent preferably before meeting the people from a high-context culture (Dulek, Fielden, and Hill, 1991).

In addition, conducting business in high-context cultures is often done in an informal setting such as dinner. Sharing dinner in China can be important in building relationships that lead to the necessary trust level to conduct business (Caroll and Hwang, 1992). In summary, personal contacts are crucial for conducting business in China. Consequently, American firms doing business in China may want to consider establishing personal relationships (Hall and Hall, 1990).

In contrast, Americans are accustomed to short term relationships (Hall and Hall, 1990). Conducting business in the United States (medium/low-context) is often done on an impersonal basis and the value of the transaction is evaluated solely on the merit of the transaction itself, not on the person who conducts the transaction. Also, the Americans look at the personal achievements in order to get a sense of a person, in contrast to the Chinese who look for qualities within a person. Americans trust a person based on his/her achievements, other people's recognition, and ranking of that person in an organization or society (Harris and Moran, 1981).

Thus, personal relationships in business are very important to the Chinese whereas Americans put more emphasis on achievements and inherent merit of the transaction itself.

\section{HYPOTHESES}

Based on the research questions: (1) Do low-context and high-context cultures differ in the amount of verbal information they need? (2) If an Internet advertisement contains only pictures, will the amount of information extracted from the Ad very greatly, depending on the context of the culture? Here is the research diagram:

Type of Ad Level of Understanding

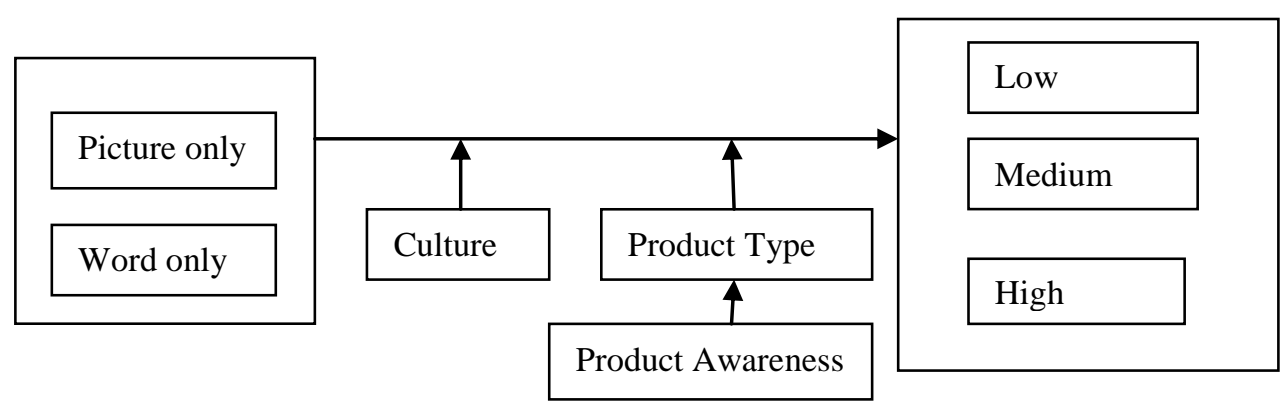

This paper develops the hypotheses:

(1) Ho: When faced with the picture only internet Advertisement, there is no difference in perception of amount of information among Germans, Americans, and Chinese.

Ha: When faced with the picture only internet Advertisement, the Germans will perceive the internet Ad as containing the least amount of information, while the Americans perceive the Ad as containing more information and the Chinese the most.

(2) Ho: When faced with the words only Advertisement, there is no difference in perception of the amount of information contained in the internet Ad among Germans, Americans, and Chinese.

Ha: When faced with the words only Advertisement, there is difference in perception of the amount of information contained in the internet Ad among Germans, Americans, and Chinese. 


\section{RESEARCH DESIGN FOR DATA COLLECTION AND ANALYSIS}

The following explains the research design used for data collection and to test the hypotheses stated previously. For this study computers were selected because of the worldwide familiarity of the product and it is marketed internationally. This is important for the study since it is a comparison among three different countries: Germany, United States, and China. Therefore, it is important that the test subjects in these three countries are familiar with and use the product frequently.

Internet advertising was chosen as the medium due to time and financial limitations. For each country, a picture only and a word only advertisements were developed. The picture only ad contains a picture of the product, the fictitious brand name, and a background scene of an object. Since an important dimension of computers is speed, a spaceship was chosen as the object for the picture only advertisement. APEX 2005 was chosen for the fictitious computer brand name.

The word only advertisement contains a description and fictitious brand name. The description of the product focused on its attributes. Each advertisement were translated into German and Chinese.

A questionnaire was developed to measure subject's responses to the various experimental treatments. A sample of the questionnaire can be found in the appendix. The first part of the questionnaire was designed to evaluate the subject's perception of quality and overall attitude towards the advertisements, either picture only or words only, and the advertised products. Specifically, question Ia asks the subjects to rate the advertisements using a 5-point Likert scale where 1 represents strongly agree and 5 for strongly disagree. Question Ib inquires about the test subjects' perception of the overall product using the same Likert scale. Question II asks the respondents how likely they thought the products contained certain attributes.

The second part of the questionnaire was related to the subjects' general purchasing behavior. The first two questions probed the respondents about how comfortable they feel with direct and indirect channels and/or with purchasing from an unfamiliar or familiar salesperson. The last two questions inquire about the type of contract agreement they feel most comfortable with: written or oral and with or without great detail. The last part of the questionnaire asked the respondents for demographic information such as their gender and nationality.

After the English version of the questionnaire was developed, the German and Chinese versions were developed. Great care was taken to ensure consistency and equivalency in each version.

To measure the content validity of the questionnaire's items, a Q-sort was conducted using expert judges. The judges placed the randomly ordered questions into piles. After several Q-sorts, the item pool was reduced. These were included in the draft instrument.

The internal consistency of the scales made up of the items identified in the Q-sort was tested. Tests were performed on several different samples. The usable responses were factor analyzed. The items with factor loadings of lower than .50 were not retained. These scales, incorporating the highest scoring items for each factor were tested for reliability. Cronbach alpha of internal consistency of above was 0.70 . Thus, the scales were internally consistent.

After the initial translations into the target languages were finished, the questionnaires were presented to a German and Chinese natives familiar with English and with the original questionnaire and to comment on its sentence structure, grammar, and equivalence of meaning.

A factorial design was undertaken to test the hypothesis. The treatments consisted of the type of culture: high-context (China), medium/low-context (United States), and low-context (Germany) and the type of advertisement (verbal verses visual). Subjects were randomly assigned to the treatment cell. The questionnaire informed the test subjects on the front page that participation in the questionnaire is voluntary. Furthermore, the confidentiality was maintained since the subjects were asked to disclose only gender and nationality. 
The German, Chinese, and American versions of the questionnaire, along with cover letters informing the respondents of the questionnaires' purpose were distributed. The specific procedure is provided in the chart below:

Chart 1: Procedures

\begin{tabular}{|c|c|c|}
\hline Description & Group A & Group B \\
\hline Distribute & Questionnaires & Questionnaires \\
\hline View & Picture only & Words only \\
\hline Answer & Questions & Questions \\
\hline
\end{tabular}

\section{STATISTICAL TREATMENTS}

This summarizes the results of the experiment. The test subjects were from Germany, United States, and China. There were two groups: group A was exposed to the picture only ad and group B was exposed to the words only ad. The data was analyzed using ANOVA and the chi square test.

\section{ANALYSIS OF FINDINGS}

A test was conducted to determine if the picture only group, group A, considered the ad to be highly visual and if the words only group, group B, considered the ad to be highly visual. A five-point Likert scale was used where 1 represented highly verbal and 5 represented highly visual. The picture only group's mean is 4.2 . This indicates the picture only group considers the ad highly visual. Furthermore, the words only group's mean is 2.3. This indicates the words only group considers the ad highly verbal. The results are significant with an F-value of 44.07 and $\mathrm{p}$ of 0.00 .

Hypotheses 1, the Germans will perceive the picture only Internet Ad as containing the least amount of information, while the Americans perceive the Ad as containing more information and the Chinese the most. Hypotheses 2 stated that there would be no difference in perception of the amount of information contained in the words only Internet Ad among Germans, Americans, and Chinese. The results of the perception of the amount of information are summarized in the table below.

Table 1: Perception of the Amount of Information

\begin{tabular}{|c|c|c|c|c|c|c|c|c|c|c|}
\hline \multirow[t]{3}{*}{ Item } & \multicolumn{5}{|c|}{ Picture Only } & \multicolumn{5}{|c|}{ Words Only } \\
\hline & & Tean* & & & & & Gean* & & & \\
\hline & Germany & U.S. & China & $\mathrm{F}$ & $\mathrm{P}$ & Germany & U.S. & China & $\mathrm{F}$ & $\mathrm{P}$ \\
\hline Computer & 4.2 & 4.2 & 3.2 & 11.2 & 0.0 & 2.3 & 2.3 & 2.7 & 2.8 & 0.1 \\
\hline
\end{tabular}

*Based on a five-point scale where 1 represented informative and 5 uninformative.

A five-point Likert scale was used where 1 represented informative and 5 represented uninformative. For the picture only ad, $\mathrm{p}$ is 0.0 showing there is significant difference in perception of the amount of information between Chinese and Americans and between Chinese and Germans. However, there is no difference in perception of the amount of information between Americans and Germans. The mean score for China is 3.2, 4.2 for Americans, and 4.2 for Germans. Based on these results, the conclusion can be made that hypothesis 1 is not supported for the computer ad.

For the words only ad, there is a small difference in perception of the amount of information between the Chinese and Americans and between the Chinese and Germans. This difference is not significant with a p-value of 0.1 for the computer ad. Furthermore, there is no difference in perception of the amount of information between the Americans and Germans. The mean score for China is 2.7, 2.3 for Americans, and 2.3 for Germans. Therefore, hypothesis 2 is not supported. 


\section{SUMMARY/CONCLUSIONS/RECOMMENDATIONS}

The results didn't provide support for the hypotheses H1 and H2. The Chinese perceived the picture only ad to have more information than the Americans and Germans. The Americans and Germans perceived the picture only ad to have the same amount of information. Additionally, there is no significant difference among Chinese, Americans, and Germans for the words only ad. Since China is a high-context culture, the United States a medium/low-context culture, and Germany a low-context culture, the Chinese seem to use the background information, a picture, more than the Americans and Germans to fill in missing information. Smith (1991) indicated that people fill in the missing gaps. Furthermore, this study indicates the extent to which people fill in gaps depends on the culture they belong.

There are several limitations to the study that should be taken into consideration when interpreting the results. First, the test subjects are not representative of the population of each country. Therefore, their responses may not be representative of the general population. Second, because of time constraints, the number of test subjects participating in the study was small, 32 in each group for a total of 64 . Third, the questionnaires and advertisements were translated from English to German and English to Chinese. Although efforts were taken to ensure equivalency, there is the possibility that a version of the questionnaire was interpreted differently. Lastly, the study tested only one product.

In conclusion, further research is needed. However, from the knowledge gained in this study, researchers can build on this information and form a tool to better understand differences among the Chinese, Germans, and Americans.

\section{AUTHOR INFORMATION}

Ed Miller is a doctoral candidate at $\mathrm{H}$. Wayne Huizenga School of Business and Entrepreneurship at Nova Southeastern University. He teaches undergraduate and master level courses including global business, organizational behavior, and management.

Dr. Thomas Griffin is Professor of Decision Sciences at the H. Wayne Huizenga School of Business and Entrepreneurship at Nova Southeastern University. He teaches master level and doctoral level courses including strategy, statistics, operation management and finance.

Dr. Peter Di Paolo currently serves as an Assistant Professor of Finance and Economics at the H. Wayne Huizenga School of Business and Entrepreneurship teaching courses for both the Masters of Business Administration and the Undergraduate Business Programs and is the lead instructor for several undergraduate business courses.

Dr. Ed Sherbert is the Founder and president of Sherbert \& Associates, an international human resources consulting firm headquartered in Mauldin, South Carolina. He had twenty-five years corporate HR experience in large and small, public and private organizations. He is the co-founder of an e-commerce company located in New York City.

\section{REFERENCES}

1. Ball, Donald A. and Wendell H. McCulloch, Jr. International Business: Introduction and Essentials, Business Publications, Inc., Plano, Texas, 1985.

2. Brislin, R. W. (1970), Back-translation for cross-cultural research, Journal of Cross-Cultural Psychology, 1(3), pp. 185-215.

3. Corroll, Paul and Balbina Y. Hwang, Export Opportunities for U.S. Firms in Korea and Taiwan, Business America, (August), 3-11, 1992.

4. Cutler, D. Bob, Rajshekhar G. Javalgi, and M. Krishna Erramilli, The Visual Components of Print Advertising: A Five-country Cross-cultural Analysis, European Journal of Marketing, 26 (4), 7-20, 1992.

5. Dulek, Ronald E., John S. Fielden, and John S. Hill, International Communication: An Executive Primer, Business Horizons, 34 (1), 20-25, 1991. 
6. Engel, James F., Roger D. Blackwell, and Paul W. Miniard, Consumer Behavior, The Dryden Press, Chicago, Illinois, 1986.

7. Hall, Edward T. and Mildred Reed Hall, Understanding Cultural Differences, Intercultural Press, Inc., Yarmouth, Maine, 1990.

8. Harris, Phillip R. and Robert T. Moran, Managing Cultural Differences, Gulf Publishing Company, Houston, Texas, 1979.

9. Hofstede, Geert, Cultural constraints in management theories, Academy of Management Executives, 7(1), pp.81-94, 1993.

10. Kennedy, Jim and Anna Everest, Put Diversity in Context, Personnel Journal, 70 (9), pp. 50-54, 1991.

11. Keown, Charles F., Laurence W. Jacobs, Richard W. Schmidt, and Kyung-Il Ghymn, Information Content of Advertising in the United States, Japan, South Korea, and the People's Republic of China, International Journal of Advertising, 11, 257-267, 1992.

12. Miracle, Gordon E., Kyu Yeol Chang, and Charles R. Taylor, Cultural and Advertising Executions: A Comparison of Selected Characteristics of Korean and US Television Commercials, International marketing Review, 9 (4), 5-17, 1992.

13. Resnik, Alan and Bruce C. Stern, An Analysis of Information Content in Television Advertising, Journal of Advertising, 41 (1), 50-53,1977.

14. Smith, Ruth Ann, The Effects of Visual and Verbal Advertising Information on Consumers' Inferences, Journal of Advertising, XX (4), 13-24,1991

15. Stanton Williams J., Michael J. Etzel, and Bruce J. Walker (1994), Fundamentals of Marketing, McGrawHill, New York, New York.

16. Zandpour, Fred, Cypress Chang, and Joelle Catalano, Stories, Symbols, and Straight Talk: A Comparative Analysis of French, Taiwanese, and U.S. TV Commercials, Journal of Advertising Research, 32 (January/February), 25-38, 1992.

\section{APPENDIX A}
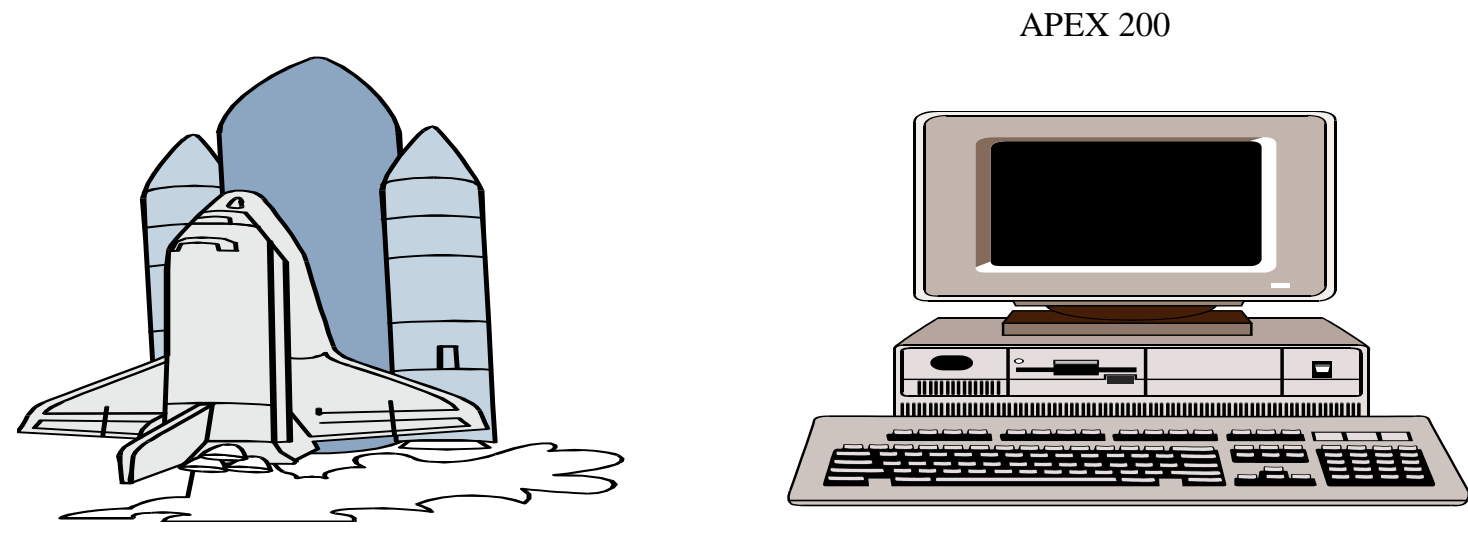

When it comes to speed the world agrees.

Over 2000 worldwide

have indicated that speed

is of invaluable importance.

APEX 2005 has responded.

APEX 2005 Specs

- Fast 486 DX2/66 Performance

- $8 \mathrm{MB}$ RAM

- $340 \mathrm{MB}$ Hard Drive

- 15 " Monitor 
Thank you for participating in this survey. Please read the questions carefully and fill them out according to your opinion. Participating in this survey is voluntary.

IA. For each of the items below, rate the advertisement for computers you were just exposed to on a scale of 1 to 5 where: $\quad 1$ stands for strongly agree

$$
\begin{aligned}
& 2 \text { stands for agree } \\
& 3 \text { stands for neither agree nor disagree } \\
& 4 \text { stands for disagree } \\
& 5 \text { stands for strongly disagree }
\end{aligned}
$$

\begin{tabular}{|c|c|c|}
\hline The Advertisement is: & $\begin{array}{l}\text { Good } \\
\text { Likable } \\
\text { Interesting } \\
\text { Informative } \\
\text { Persuasive } \\
\text { Highly verbal }\end{array}$ & 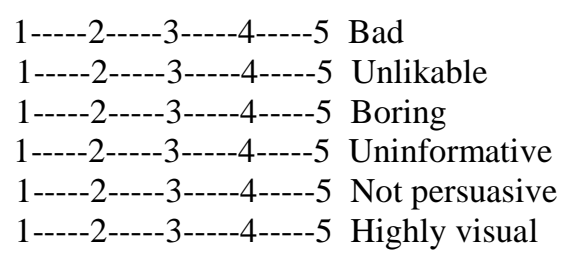 \\
\hline
\end{tabular}

IB. For each of the items below, rate the advertised computer you were just exposed to using the same 5-point scale as in question IA.

The advertised product is:

$$
\begin{array}{lll}
\text { Good } & \text { 1-----2-----3-----4-----5 } \text { Bad } \\
\text { Likable } & 1-----2----3----4----5 \text { Unlikable } \\
\text { High Quality } & \text { 1-----2-----3----4-----5 Low Quality } \\
\text { Dependable } & \text { 1-----2-----3----4-----5 Not Dependable }
\end{array}
$$

II. Please indicate how likely or unlikely the advertised computer you were exposed to possesses the following product attributes using a 5-point scale where:

$$
\begin{aligned}
& 1 \text { stands for very likely } \\
& 2 \text { stands for likely } \\
& 3 \text { stands for neither likely nor unlikely } \\
& 4 \text { stands for unlikely } \\
& 5 \text { stands for very unlikely }
\end{aligned}
$$

\begin{tabular}{|c|c|c|}
\hline $\begin{array}{l}\text { very } \\
\text { likely }\end{array}$ & likely & neither \\
\hline
\end{tabular}

The Apex 2005 computer:

- is well built

- has an excellent memory capacity

- has a high processing speed

- is reliable

- $\quad$ is expensive

$$
\begin{aligned}
& \text { 1-----2-----3-----4------5 } \\
& \text { 1-----2-----3----44----5 } \\
& \text { 1-----2-----3-----4-----5 } \\
& \text { 1-----2-----3-----4-----5 } \\
& \text { 1-----2-----3-----4-----5 }
\end{aligned}
$$

The following questions are related to your general purchase behavior. Please do not take the advertised products in consideration when answering these questions. Please answer the following questions as honestly as you can.

a. The product you want to buy is available through direct channels, such as mail or telephone order, as well as through retail stores. How likely will you buy through direct channels?

b. I prefer to buy things from a salesperson I know.

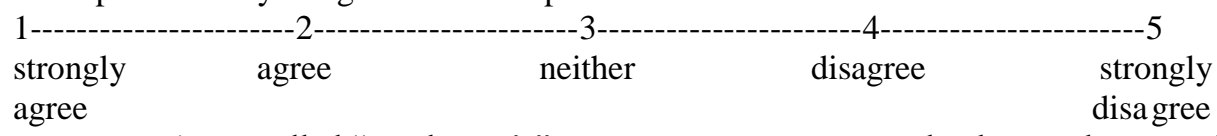

c. I trust the so-called "gentleman's" agreement, an agreement that has not been put into writing.

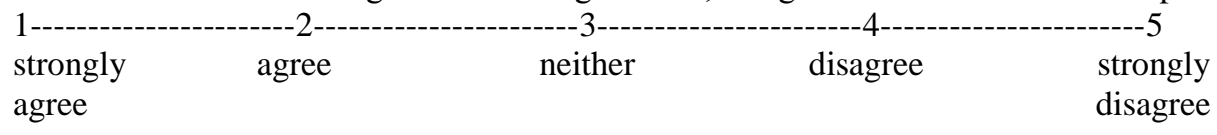


d. I prefer to spell out in great detail the agreement I have with others.

\begin{tabular}{|c|c|c|c|}
\hline $\begin{array}{l}\text { strongly } \\
\text { agree }\end{array}$ & agree & neither & disagree \\
\hline
\end{tabular}

Biographical information

a. my gender

b. my nationality

$\begin{array}{ll}\text {---male } & \text {---female } \\ \text {--US } & \text {---German } \\ & \text {---Republic of China } \\ & \text {---Other (specify) }\end{array}$

\section{NOTES}


NOTES 